REVIEW

\title{
A review of the stroke volume response to upright exercise in healthy subjects
}

\author{
C A Vella, R A Robergs
}

Br J Sports Med 2005;39:190-195. doi: 10.1136/bjsm.2004.013037

Traditionally, it has been accepted that, during incremental exercise, stroke volume plateaus at $40 \%$ of $\mathrm{VO}_{2} \mathrm{MAX}$. However, recent research has documented that stroke volume progressively increases to $\mathrm{VO}_{2} \mathrm{MAX}$ in both trained and untrained subjects. The stroke volume response to incremental exercise to $\mathrm{VO}_{2} \mathrm{MAX}$ may be influenced by training status, age, and sex. For endurance trained subjects, the proposed mechanisms for the progressive increase in stroke volume to $\mathrm{VO}_{2} \mathrm{MAX}$ are enhanced diastolic filling, enhanced contractility, larger blood volume, and decreased cardiac afterload. For untrained subjects, it has been proposed that continued increases in stroke volume may result from a naturally occurring high blood volume. However, additional research is needed to evaluate the importance of blood volume, or other mechanisms, that influence the stroke volume response to exercise in untrained subjects.

See end of article for authors' affiliations

Correspondence to: Dr Vella, University of New Mexico, MSC 04 2610, 1, Albuquerque 87131, USA; cvella@salud.unm.edu

Accepted 22 August 2004

\section{HISTORICAL PERSPECTIVE}

It is commonly accepted that, during incremental, upright exercise to maximum, stroke volume increases from rest to exercise and plateaus at $40-50 \%$ of $\mathrm{VO}_{2}$ MAX. ${ }^{1}$ The theory of a stroke volume plateau developed from early research based on a few subjects during two or three exercise intensities, ${ }^{1-3}$ with the latter characteristic limiting the number of data points used to describe the stroke volume response to exercise. ${ }^{23}$ The concept of a plateau in stroke volume was attributed mainly to a decrease in the diastolic filling time that occurs during exercise of increasing intensity. ${ }^{4}$

Interestingly, a progressive increase in stroke volume was reported in the literature as early as 1960. In a study by Chapman and others ${ }^{5}$ the stroke volume responses during discontinuous treadmill exercise were evaluated in 26 normal, male subjects aged 19-63 years. The fitness level of the subjects was not noted, but the mean (SD) $\mathrm{VO}_{2} \mathrm{MAX}$ was 3.38 (0.46) litres/min. Stroke volume increased progressively with increasing levels of exercise in most subjects, but the relation between stroke volume and $\mathrm{VO}_{2}$ was not linear. Similarly, Ekblom and Hermansen ${ }^{6}$ reported that stroke volume progressively increased during treadmill exercise at workloads of $40-80 \%$ of $\mathrm{VO}_{2} \mathrm{MAX}$ and at $\mathrm{VO}_{2} \mathrm{MAX}$ in nine of 13 well trained athletes (subject sex was not stated). Unfortunately, these findings were largely ignored and it became accepted that stroke volume plateaus during exercise of increasing intensity.

More recent investigations have reported that stroke volume progressively increases in certain people..$^{7-12}$ The mechanisms for the continual increase in stroke volume are not completely understood. Gledhill et $a l^{7}$ proposed that enhanced diastolic filling and subsequent enhanced contractility are responsible for the increased stroke volume in trained subjects. However, an increase in stroke volume with an increase in exercise intensity has also been reported in untrained subjects. ${ }^{8}{ }^{9}$ Table 1 presents a summary of the past research that has quantified stroke volume during exercise.

Current research indicates that there is a range of responses in stroke volume to reflect the range of a subject's training status. In addition, training may not be the only factor affecting the stroke volume response to exercise. Four main types of stroke volume responses to exercise have been reported in the literature: plateau, ${ }^{1}$ 10 $^{13-16}$ plateau with a drop, ${ }^{14}$ 15 $^{17-19}$ plateau with a secondary increase, ${ }^{51120}$ and progressive increase $e^{6-10121421}$ (fig l). The implications of a progressive increase in stroke volume to $\mathrm{VO}_{2} \mathrm{MAX}$ have yet to be completely understood.

This review will examine recent discussions and evidence describing the stroke volume response to increasing exercise intensity. In addition, the role of fitness level, age, and sex on the stroke volume response to incremental exercise will be clarified.

\section{FITNESS LEVEL}

Gledhill and coworkers ${ }^{7}$ were the first to recognise the difference in the stroke volume response between trained and untrained young men. The study compared the stroke volume response in competitive, male endurance cyclists (22.5 (2.1) years; mean (SD)) and normally active males (22.2 (4.9) years) at matched heart rates ranging from 90 tol 90 beats/min during cycle ergometry. The stroke volume of the competitive endurance cyclists increased progressively throughout exercise, whereas that of the normally active males plateaued at an average heart rate of 120 beats/ min or $40 \%$ of $\mathrm{VO}_{2}$ MAX. In addition, the stroke volumes of the trained subjects were significantly larger than those of the untrained subjects at all heart rates $(\mathrm{p}<0.001)$.

There is accumulating evidence that, in some endurance trained men and women, stroke volume continues to increase to $\mathrm{VO}_{2} \mathrm{MAX}$. Zhou 
Table 1 Summary of the literature on stroke volume response to exercise

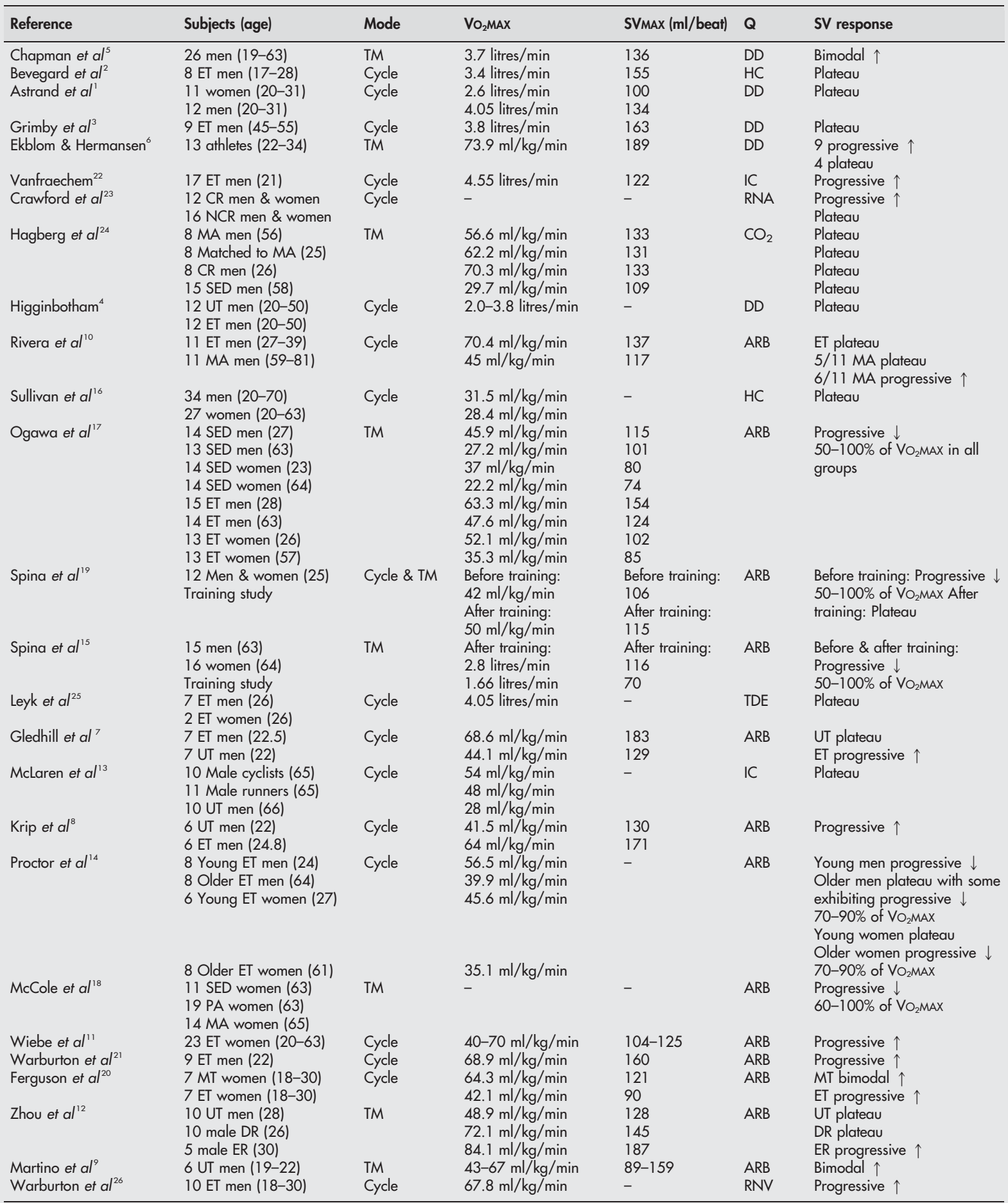

Data are presented as the mean or range.

SV, Stroke volume; ET, endurance trained; UT, untrained; PA, physically active; MT, moderately trained; MA, master athlete; DR, distance runners; ER, elite runners; CR, competitive runners; NCR, non-competitive runners; SED, sedentary; TM, Treadmill; DD, dye dilution; ARB, acetylene rebreathing; TDE, two dimensional echo; $\mathrm{HC}$, heart catheter; $\mathrm{IC}$, impedance cardiography; $\mathrm{CO}_{2}, \mathrm{CO}_{2}$ rebreathing; $\mathrm{RNA}$, radionuclide angiography; RNV, radionuclide ventriculography.

et $a^{12}$ compared the stroke volume response in untrained men (28.1 (7.5) years), male distance runners (25.5 (4.3) years), and elite male runners (29.8 (2.5) years) during incremental exercise to exhaustion on the treadmill. The stroke volume of the untrained and distance runners plateaued at about $40 \%$ of $\mathrm{VO}_{2} \mathrm{MAX}$, whereas in elite distance runners, it continued to increase throughout exercise to maximum. Although the distance runners' $\mathrm{VO}_{2} \mathrm{MAX}$ averaged $72.1 \mathrm{ml} / \mathrm{kg} / \mathrm{min}$, $12 \mathrm{ml} / \mathrm{kg} / \mathrm{min}$ lower than that of the elite runners, they still exhibited a plateau in stroke volume, indicating that endurance training may not be the only factor influencing the stroke volume response to exercise.

Crawford $e t a^{23}$ studied the stroke volume response in male and female competitive marathon runners and 


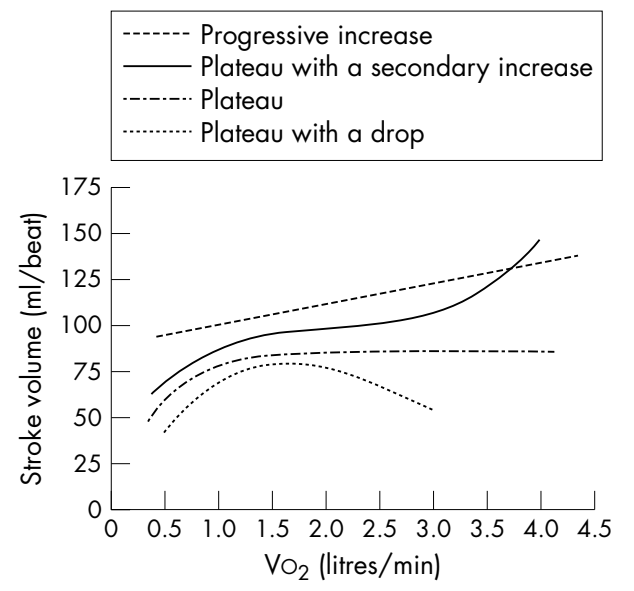

Figure 1 The four types of stroke volume response with increasing exercise intensity.

non-competitive runners. The stroke volume of the noncompetitive runners plateaued at $70 \%$ of maximal heart rate, whereas that of the competitive marathon runners progressively increased to maximal heart rate. Although the stroke volume of the latter group progressively increased to maximal heart rate, the authors noted that the increase in stroke volume from $70 \%$ to $100 \%$ of maximal heart rate was not significant.

Vanfraechem $^{22}$ studied healthy, male soccer players (21 (0.2) years) during cycle exercise at 25,50 , and $75 \%$ of $\mathrm{VO}_{2} \mathrm{MAX}$ and reported significant increases in stroke volume at each workload. Although stroke volume was not measured at an intensity greater than $75 \%$ of $\mathrm{VO}_{2} \mathrm{MAX}$, this study suggested that it may not plateau in young, healthy male soccer players.

Warburton and coworkers ${ }^{21}$ studied the stroke volume response in male endurance trained cyclists during incremental exercise to $\mathrm{VO}_{2} \operatorname{MAX}(22$ (1) years) under two conditions: a $500 \mathrm{ml}$ plasma volume expansion and control. In both the plasma volume expansion and control trials, stroke volume increased progressively throughout incremental cycle exercise to $\mathrm{VO}_{2} \mathrm{MAX}$. In addition, stroke volume and cardiac output were elevated after plasma volume expansion, suggesting that blood volume has a significant influence on the stroke volume response to exercise. Warburton et $a^{26}$ reported similar findings in highly trained male cyclists (1830 years) during supine and upright cycle exercise to $\mathrm{VO}_{2} \mathrm{MAX}$. In both supine and upright exercise, stroke volume increased progressively to $\mathrm{VO}_{2} \mathrm{MAX}$.

In contrast, Spina et a $^{19}$ reported a plateau in stroke volume after 12 weeks of endurance training in healthy sedentary men and women (25 (1) years). Before endurance training, stroke volume fell significantly in all subjects when exercise intensity was increased from $50 \%$ to $100 \%$ of $\mathrm{VO}_{2} \mathrm{MAX}$. The authors concluded that endurance training attenuated the decrease in stroke volume at maximal exercise.

Rivera et $a l^{10}$ also reported a plateau in stroke volume in endurance trained younger and older men. All of the young athletes (27-39 years) and five of 11 master athletes (59-81

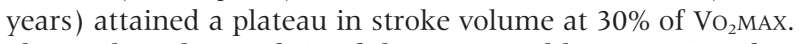
The stroke volume of six of the master athletes continued to increase to $85 \%$ of $\mathrm{VO}_{2} \mathrm{MAX}$, but the increase in stroke volume from $30 \%$ to $85 \%$ of $\mathrm{VO}_{2} \mathrm{MAX}$ was not significant.

Similarly, unpublished data from our laboratory suggested that not all endurance trained subjects exhibit a progressive increase in stroke volume during incremental exercise to $\mathrm{VO}_{2} \mathrm{MAX}$. We tested 21 endurance trained men and women (29.4 (6.1) years) during cycle exercise to $\mathrm{VO}_{2} \mathrm{MAX}$. Eighteen subjects reached a plateau in stroke volume at $37 \%$ of $\mathrm{VO}_{2} \mathrm{MAX}$, with one subject unable to maintain maximal stroke volume as exercise intensity increased to $\mathrm{VO}_{2} \mathrm{MAX}$. Only three subjects showed a progressive increase in stroke volume to $\mathrm{VO}_{2} \mathrm{MAX}$.

Although most of the available data on the stroke volume response to exercise are from male subjects, there is also evidence to support a progressive increase in stroke volume in female subjects. Ferguson $e a^{20}$ compared the stroke volume response in moderately active and endurance trained women (18-30 years) during incremental cycle exercise to exhaustion. Stroke volume increased progressively to $\mathrm{VO}_{2} \mathrm{MAX}$ in both groups. The stroke volume was significantly greater in endurance trained women at all workloads. In moderately trained women, stroke volume increased from rest to exercise, plateaued, and then showed a secondary increase to maximum. Wiebe and colleagues ${ }^{11}$ reported similar results in women 20-63 years of age. This type of rise in stroke volume is consistent with data from others. ${ }^{5}{ }^{11}$

Three studies to date provide evidence that stroke volume does not plateau in untrained subjects. ${ }^{59}$ Martino and colleagues ${ }^{9}$ studied healthy, young men (19-22 years) with no history of training, but unusually high $\mathrm{VO}_{2} \mathrm{MAx}$. Untrained subjects with a high $\mathrm{VO}_{2} \operatorname{MAX}(65.3(0.6) \mathrm{ml} / \mathrm{kg} / \mathrm{min}$; HI group) were matched with similar subjects who had a normal $V_{O_{2}} \operatorname{MAX}(46.2(0.9) \mathrm{ml} / \mathrm{kg} / \mathrm{min}$; LO group). Subjects were chosen from a group of 1900 healthy, young men who underwent prior $\mathrm{VO}_{2} \mathrm{MAX}$ testing. Despite no history of training, the $\mathrm{VO}_{2} \mathrm{MAX}$ and mean blood volume of the $\mathrm{HI}$ group were comparable with that of an endurance trained athlete. In both groups, stroke volume increased progressively from rest to $50 \%$ of $\mathrm{VO}_{2} \mathrm{MAX}$, plateaued from $50 \%$ to $75 \%$ of $\mathrm{VO}_{2} \mathrm{MAX}$, then increased from $75 \%$ to $100 \%$ of $\mathrm{VO}_{2} \mathrm{MAX}$. Martino and colleagues concluded that the high $\mathrm{VO}_{2} \mathrm{MAX}$ observed in the untrained subjects was due to a naturally occurring high blood volume that contributes to a high maximal stroke volume and cardiac output. Krip and colleagues $^{8}$ reported similar results in endurance trained male cyclists and untrained male control subjects (18-30 years) during cycle exercise to exhaustion. The stroke volume of all of the subjects increased progressively throughout exercise to $\mathrm{VO}_{2} \mathrm{MAX}$, although the trained subjects had higher blood volumes, faster diastolic filling rates, and faster systolic emptying rates than the untrained controls.

Current research supports a continual increase in stroke volume during exercise of increasing intensity in some trained and untrained subjects. The physiological characteristics that promote this progressive increase are not yet fully understood. Data support endurance training as a mechanism of improving the stroke volume response to exercise. However, the data of Martino et al ${ }^{9}$ show that blood volume, independent of training, may be a major determinant of the stroke volume response to exercise.

\section{AGE}

Studies on the effects of age on the stroke volume response to exercise have produced conflicting results. Whereas most studies have reported a plateau or a fall in stroke volume, ${ }^{14151718}$ two have reported a progressive increase in stroke volume in older men and women. ${ }^{10}{ }^{11}$ The age related effects on the stroke volume response to exercise may be due to increases in end systolic volume, decreases in end diastolic volume, or a combination of both.

The results of Wiebe et $a l^{11}$ and Rivera et $a l^{10}$ provide evidence of a progressive increase in stroke volume in older subjects. Wiebe and others ${ }^{11}$ examined the stroke volume response during incremental cycle exercise to $\mathrm{VO}_{2} \mathrm{MAX}$ in endurance trained women (20-63 years). The subjects were matched for lean body mass, then divided into four age groups: 20-29, 40-45, 49-54, and 58-63 years. In all groups, stroke volume increased progressively throughout 
incremental exercise to $\mathrm{VO}_{2} \mathrm{MAX}$. Maximal stroke volume was lower in endurance trained women aged 40-63 years than in those aged 20-29 years. The authors hypothesised that the age related differences in maximal stroke volume may be due to decreases in end diastolic volume or end systolic volume. These data suggest that older subjects have the ability to progressively increase stroke volume during exercise of increasing intensity.

Rivera and colleagues ${ }^{10}$ reported similar results when comparing the stroke volume response of master athletes (59-81 years) and young athletes (27-39 years) during incremental treadmill exercise to $85 \%$ of $\mathrm{VO}_{2} \mathrm{MAX}$. The stroke volume of all of the young runners and five of 11 master runners plateaued during exercise, whereas the stroke volume of the other six master runners progressively increased to $85 \%$ of $\mathrm{VO}_{2} \mathrm{MAX}$. The authors noted that, in all groups, the average stroke volume did not significantly increase after $30 \%$ of $\mathrm{VO}_{2} \mathrm{MAX}$; however, visual inspection of individual data revealed that stroke volume progressively increased in six of 11 master runners.

In contrast, several authors have reported a plateau or fall in stroke volume during exercise in older subjects. ${ }^{13} 141718$ Proctor and others ${ }^{14}$ compared younger (20-31 years) and older (51-72 years) endurance trained men and women during cycle exercise at $40 \%, 70 \%$, and $90 \%$ of $\mathrm{VO}_{2} \mathrm{MAX}$. The stroke volume in the young men continued to increase progressively throughout exercise to $90 \%$ of $\mathrm{VO}_{2} \mathrm{MAX}$, whereas the stroke volume of older men and younger women exhibited a plateau which was maintained throughout exercise. The older women showed an impaired ability to maintain stroke volume when intensity was increased from $70 \%$ to $90 \%$ of $\mathrm{VO}_{2} \mathrm{MAX}$. Several of the oldest men also showed a modest decline in stroke volume at exercise intensities above $70 \%$ of $\mathrm{VO}_{2} \mathrm{MAX}$. The authors noted that the stroke volume response in both the older men and women was related to age $(r=-0.50)$, with the oldest subjects having the largest decrease in stroke volume.

McCole et al ${ }^{18}$ reported similar results in postmenopausal competitive master athletes, physically active women, and sedentary women $(63(5)$ years $)$ during treadmill exercise to $\mathrm{VO}_{2} \mathrm{MAX}$. In all groups, stroke volume reached maximal values at $40-60 \%$ of $\mathrm{VO}_{2} \mathrm{MAX}$ and decreased significantly as exercise intensity increased from $60 \%$ to $100 \%$ of $\mathrm{VO}_{2} \mathrm{MAX}$. The decrease in stroke volume was similar across all physical activity groups.

Ogawa et $\mathrm{l}^{17}$ studied healthy younger (18-31 years) and older (51-72 years) sedentary and endurance trained men and women. The subjects were divided into eight groups based on age (younger versus older), training status (sedentary versus trained), and sex. In all groups, the highest stroke volume was attained at $50 \%$ of $\mathrm{VO}_{2} \mathrm{MAX}$, and a fall in stroke volume occurred between $50 \%$ and $100 \%$ of $\mathrm{VO}_{2} \mathrm{MAX}$.

Hagberg et al $^{24}$ compared master athletes (56 (5) years), young runners matched in training and performance to the master athletes (25 (3) years), competitive young runners (26 (3) years), and healthy older sedentary subjects (58 (5) years) during treadmill exercise at $50 \%, 60 \%$, and $70 \%$ of $\mathrm{VO}_{2} \mathrm{MAX}$. In all groups, stroke volume plateaued at $50 \%$ of $\mathrm{VO}_{2} \mathrm{MAX}$ and was maintained up to $70 \%$ of $\mathrm{VO}_{2} \mathrm{MAX}$. Although the stroke volume of the older subjects did not decline, stroke volume measurements were only obtained up to $70 \%$ of $\mathrm{VO}_{2}$ MAX. Several studies have reported a fall in stroke volume at intensities above $70 \%$ of $\mathrm{VO}_{2} \mathrm{MAX}$ in older subjects, ${ }^{14} 1718$ therefore it is difficult to ascertain if the plateau in stroke volume in older subjects would have been maintained up to $\mathrm{VO}_{2} \mathrm{MAX}$.

McLaren and colleagues ${ }^{13}$ reported a stroke volume plateau in trained older male cyclists (65 (2.1) years), trained older male runners (65 (3.5) years), and healthy but untrained older male controls (66 (1.2) years). The stroke volume of the older trained runners plateaued at about $40 \%$ of $\mathrm{VO}_{2} \mathrm{MAX}$, whereas the stroke volume of the older trained cyclists and controls plateaued at an average of $30 \%$ of $\mathrm{VO}_{2} \mathrm{MAX}$.

In a training study by Spina et al, ${ }^{15}$ the stroke volume of older men and women decreased as exercise intensity increased from $50 \%$ to $100 \%$ of $\mathrm{VO}_{2} \mathrm{MAX}$ before and after 9-12 months of endurance training, suggesting that the adaptability in the stroke volume response to exercise may be influenced by age.

Current evidence indicates that older subjects (men and women) have an impaired ability to maintain stroke volume at near maximal exercise. Although there is evidence of a progressive increase in stroke volume in older subjects, additional longitudinal research is needed to evaluate the effects of age on the stroke volume response to exercise.

\section{SEX DIFFERENCES}

The studies on sex differences in the stroke volume response to exercise have produced conflicting results. Sullivan and others ${ }^{16}$ investigated the effects of sex on stroke volume control during cycle exercise to $\mathrm{VO}_{2} \mathrm{MAX}$ in healthy men (2070 years) and women (20-63 years). In both men and women, stroke volume reached its maximum at $50 \%$ of $\mathrm{VO}_{2} \mathrm{MAX}$ and remained unchanged through maximal exercise. There were no differences in stroke volume index $\left(\mathrm{ml} / \mathrm{m}^{2}\right)$ at rest or during exercise between groups. In addition, the increase in stroke volume index from rest to exercise was similar in men and women. These authors concluded that, in healthy subjects, matched for body size and fitness level, sex is not an important determinant of the stroke volume response to exercise.

In contrast, although Ogawa et $a l^{17}$ reported similar stroke volume responses in healthy younger (18-31 years) and older (52-27 years) sedentary and endurance trained men and women, the stroke volume of the women was lower at all workloads compared with the men, even after normalisation to body weight. After normalisation of stroke volume to fat free mass, the sex difference was eliminated in sedentary subjects, but only reduced in the endurance trained subjects. The authors concluded that the sex difference in the stroke volume of the endurance trained subjects was due to a greater percentage of body fat in women.

Proctor and others ${ }^{14}$ examined the influence of age and sex on cardiovascular responses to exercise. The stroke volume response of younger (20-31 years) and older (51-72 years) endurance trained men and women were compared during cycle exercise at $40 \%, 70 \%$, and $90 \%$ of $\mathrm{VO}_{2} \mathrm{MAX}$. The stroke volume in the young men had not yet reached a plateau at $90 \%$ of $\mathrm{VO}_{2} \mathrm{MAX}$, whereas the stroke volume of older men and younger women reached a plateau at $40 \%$ of $\mathrm{VO}_{2} \mathrm{MAX}$ which was maintained throughout exercise. The older women showed an impaired ability to maintain stroke volume at exercise intensities above $90 \%$ of $\mathrm{VO}_{2} \mathrm{MAX}$, which was also evident, to a lesser degree, in the oldest men. Spina and coworkers $^{15}$ studied sex differences in the cardiovascular responses before and after training in older men and women (64 (3) years). Before and after training, stroke volume decreased as exercise intensity was increased from $50 \%$ to $100 \%$ of $\mathrm{VO}_{2} \mathrm{MAX}$ in both sexes. However, the decrease in stroke volume was greater in women than in men.

Current evidence suggests that the stroke volume response to exercise may differ between men and women. However, sex differences cannot be elucidated at this time because of conflicting results and a lack of relevant studies.

\section{MECHANISMS OF ENHANCED STROKE VOLUME}

With increasing exercise intensity, diastolic filling time, as well as systolic ejection time, decreases. ${ }^{7}$ This decrease is 


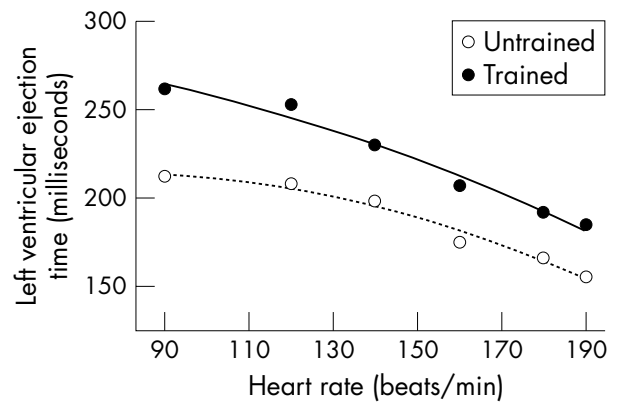

Figure 2 Comparison of ventricular ejection time between trained and untrained subjects. Adapted from Gledhill et al. ${ }^{7}$

thought to lead to a plateau in stroke volume with increasing exercise intensity. However, current research is suggesting that, in young endurance trained subjects, diastolic filling, as well as ventricular emptying, is enhanced, leading to a progressive increase in stroke volume during exercise to $\mathrm{VO}_{2}$ MAX. $^{720}$ Interestingly, research has shown that endurance trained subjects have significantly longer ventricular ejection times, ${ }^{7827}$ greater myocardial contractility, ${ }^{1622}$ greater left ventricular diameter and mass, ${ }^{28-31}$ and significantly shorter diastolic filling times ${ }^{827}$ than untrained subjects.

Gledhill et al reported that, in endurance trained men, ventricular ejection times were longer, and diastolic filling times were shorter, than in untrained men (figs 2 and 3). If athletes are able to increase end diastolic volume in less time than untrained subjects, this suggests that the rates of ventricular filling are dramatically increased in trained subjects. What allows for this increased rate of filling? Gledhill and coworkers ${ }^{7}$ suggested that the higher blood volumes in the trained subjects maintained an adequate ventricular filling pressure during exercise, thereby enhancing diastolic filling. The longer ejection times and enhanced diastolic emptying reported by Gledhill et al ${ }^{7}$ were attributed to lower systolic and diastolic blood pressures in trained subjects, which reduced cardiac afterload and facilitated ventricular emptying. Further support for enhanced diastolic filling in athletes was reported by Vinereanu et al. ${ }^{31}$ Using tissue Doppler echocardiography, they reported augmented left ventricular diastolic filling velocities in endurance trained subjects compared with strength trained and control subjects.

Wolfe and others ${ }^{27}$ reported similar findings in trained male athletes. The athletes tested had shorter pre-ejection periods, longer ejection times, and faster mean systolic ejection rates at the same exercise heart rates than subjects who were moderately trained and untrained. The authors hypothesised that an enhanced end diastolic volume and ejection fraction were involved in the increased stroke volume in athletes.

\section{What is already known on this topic}

Research data on the stroke volume response to incremental exercise are conflicting. Early research supports a plateau in stroke volume in healthy untrained and trained subjects. Recent research has documented that stroke volume progressively increases to $\mathrm{VO}_{2} \mathrm{MAX}$ in both trained and untrained subjects, but this finding has not been consistently reported.

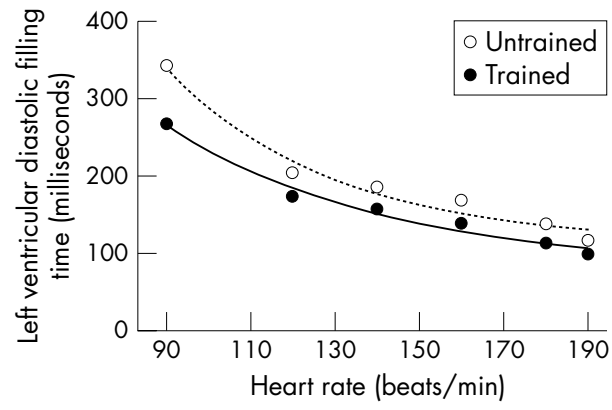

Figure 3 Comparison of ventricular diastolic filling time between trained and untrained subjects. Adapted from Gledhill et al.?

Ferguson and colleagues ${ }^{20}$ suggested that, in endurance trained women, the increase in stroke volume at higher exercise intensities was due to an enhanced ventricular preload, not myocardial contractility. In contrast, JensenUrstad and colleagues ${ }^{32}$ reported that training induced increases in myocardial contractility, and possibly a decreased afterload, were the main contributing factors to the increase in stroke volume during incremental exercise in elite male runners. Similarly, Vanfraechem ${ }^{22}$ reported that left ventricular ejection times decreased at each workload in male soccer players. The author hypothesised that the continued increase in stroke volume, despite the decrease in ventricular ejection time, may be due to an increase in ejection fraction during exercise of increasing intensity.

In addition, left ventricular eccentric hypertrophy may be related to enhanced diastolic filling and stroke volume. Data indicate that endurance trained athletes develop an increase in both left ventricular diameter and wall thickness (eccentric hypertrophy), as the heart adapts to both volume and pressure loads. ${ }^{28-31}$ Longitudinal data from Levy et $a l^{30}$ indicate that endurance training significantly increases left ventricular mass and is associated with improvements in early diastolic filling rates at rest and during exercise. Similarly, Hoogsteen et al ${ }^{29}$ reported greater left ventricular end diastolic diameter and early filling rates in endurance trained subjects compared with previously established normal values. However, data are conflicting in this area. ${ }^{28} 30$

The above findings indicate that endurance trained subjects may have enhanced diastolic filling, greater left ventricular diameter and mass, greater ventricular compliance, greater myocardial contractility, and may depend more on the Frank Starling mechanism (preload) as exercise intensity increases, compared with untrained subjects. Although research suggests that untrained subjects with a naturally occurring high blood volume may have enhanced diastolic filling, ${ }^{89}$ there is currently no evidence to suggest that untrained people have enhanced ventricular compliance, greater left ventricular diameter and mass, or myocardial contractility, as seen in trained subjects.

\section{What this study adds}

This is the first review of stroke volume responses to exercise in healthy subjects. This study adds to the understanding of the various stroke volume responses to increasing exercise intensity, the effects of endurance training, sex, and age on the stroke volume response to exercise, and the mechanisms responsible for a progressive increase in stroke volume during exercise. 


\section{CONCLUSIONS}

Current findings indicate that the stroke volume response to exercise may depend on many factors, including age, fitness level, sex, and genetics. Those with a high blood volume may be more likely to exhibit a progressive increase in stroke volume during exercise of increasing intensity. The progressive increase in stroke volume with endurance training has some training implications and clinical relevance. In terms of myocardial oxygen demand, increasing stroke volume is much more efficient than increasing heart rate during exercise. In athletes, increasing stroke volume for a given heart rate may increase work output and performance. The physiological mechanisms for an enhanced stroke volume during exercise may include enhanced diastolic filling due to increases in blood volume, left ventricular diameter, and ventricular compliance, enhanced systolic emptying due to increases in myocardial contractility and decreases in ventricular afterload, or both.

Future investigations should evaluate the type and amount of endurance training needed to facilitate a progressive increase in stroke volume during incremental exercise and determine if the adaptability in the stroke volume response to exercise is influenced by age, sex, type of training, and training status.

\section{Authors' affiliations}

C A Vella, R A Robergs, University of New Mexico, Albuquerque, New Mexico, USA

Competing interests: none declared

\section{REFERENCES}

1 Astrand PO, Cuddy TE, Saltin B, et al. Cardiac output during submaximal and maximal work. J Appl Physiol 1964;19:268-74.

2 Bevegard S, Holmgren A, Jonsson B. Circulatory studies in well trained athletes at rest and during heavy exercise, with special reference to stroke volume and the influence of body position. Acta Physiol Scand 1963;57:26-50.

3 Grimby G, Nilsson NJ, Saltin B. Cardiac output during submaximal and maximal exercise in active middle-aged athletes. J Appl Physiol 1966;21:1150-6.

4 Higginbotham MB, Morris KG, Williams, RS, et al. Regulation of stroke volume during submaximal and maximal upright exercise in normal man. Circ Research 1986;58:281-91.

5 Chapman CB, Fisher JN, Sproule BJ. Behavior of stroke volume at rest and during exercise in human beings. J Clin Investigation 1960;30:1208-13.

6 Ekblom B, Hermansen L. Cardiac output in athletes. J Appl Physiol 1968;25:619-25.

7 Gledhill N, Cox D, Jamnik R. Endurance athletes' stroke volume does not plateau; major advantage is diastolic function. Med Sci Sports Exerc 1994;26:1116-21.

8 Krip B, Gledhill N, Jamnik V, et al. Effect of alterations in blood volume on cardiac function during maximal exercise. Med Sci Sports Exerc 1997;29:1469-76.

9 Martino $M$, Gledhill N, Jamnik V. High $\mathrm{VO}_{2}$ max with no history of training is primarily due to high blood volume. Med Sci Sports Exerc 2002;34:966-71.
10 Rivera AM, Pels III, Sady AE, et al. Physiological factors associated with the lower maximal oxygen consumption of master runners. J Appl Physiol 1989;66:949-54

11 Wiebe CG, Gledhill N, Jamnik VK, et al. Exercise cardiac function in young through elderly endurance trained women. Med Sci Sports Exerc 1999;31:684-91

12 Zhou B, Conlee RK, Jensen R, et al. Stroke volume does not plateau during graded exercise in elite male distance runners. Med Sci Sports Exerc 2001;33:1849-54.

13 McLaren PF, Nurhayati Y, Boutcher SH. Stroke volume response to cycle ergometry in trained and untrained older men. Eur J Appl Physiol 1997; 57:537-42.

14 Proctor DN, Beck KC, Shen PH, et al. Influence of age and gender on cardiac output $\mathrm{VO}_{2}$ relationships during submaximal cycle ergometry. J Appl Physiol 1998;84:599-605

15 Spina RJ, Ogawa T, Kohrt WM, et al. Differences in cardiovascular adaptations to endurance exercise training between older men and women. J Appl Physiol 1993;75:849-55.

16 Sullivan MJ, Cobb FR, Higginbotham MB. Stroke volume increases by similar mechanisms during upright exercise in normal men and women. Am J Cardiol 1991;67:1405-12.

17 Ogawa T, Spina RJ, Martin III WH, et al. Effects of aging, sex, and physical training on cardiovascular responses to exercise. Circulation 1992;86:494-503.

18 McCole SD, Brown MD, Moore GE, et al. Cardiovascular hemodynamics with increasing exercise intensities in postmenopausal women. J Appl Physiol 1999:87:2334-40.

19 Spina RJ, Ogawa T, Martin III WH, et al. Exercise training prevents decline in stroke volume during exercise in young healthy subjects. J Appl Physiol 1992;72:2458-62.

20 Ferguson S, Gledhill N, Jamnik VK, et al. Cardiac performance in endurance trained and moderately active young women. Med Sci Sports Exer 2001;33:1114-17.

21 Warburton DER, Gledhill N, Jamnik VK, et al. Induced hypervolemia, cardiac function, $\mathrm{VO}_{2}$ max, and performance of elite cyclists. Med Sci Sports Exerc 1999:31:800-8.

22 Vanfraechem JHP. Stroke volume and systolic time interval adjustments during bicycle ergometer. J Appl Physiol 1979;46:588-92.

23 Crawford MH, Petru MA, Rabinowitz C. Effect of isotonic exercise training on left ventricular volume during upright exercise. Circulation 1985;72:1237-43

24 Haberg JM, Allen WK, Seals DR, et al. A hemodynamic comparison of young and older endurance trained athletes during exercise. J Appl Physiol 1985:58:2041-6.

25 Leyk D, Ebfeld D, Hoffmann U, et al. Postural effect on cardiac output, oxygen uptake and lactate during cycle exercise of varying intensity. Eur J Appl Physiol 1994;68:30-5.

26 Warburton DER, Haykowsky MJ, Quinney HA, et al. Myocardial response to incremental exercise in endurance-trained athletes: influence of heart rate, contractility and the Frank-Starling effect. Exp Physiol 2002;87:613-22.

27 Wolfe LA, Cunningham DA, Davis GM, ef al. Relationship between maximal oxygen uptake and left ventricular function in exercise. J Appl Physiol 1978;44:44-9.

28 Finkelhor RS, Hanak $\sqcup$, Bahler RC. Left ventricular filling in endurance-trained subjects. J Am Coll Cardiol 1986;8:289-93.

29 Hoogsteen J, Hoogeveen A, Schaffers $\mathrm{H}$, et al. Left atrial and ventricular dimensions in highly trained cyclists. Int J Cardiovasc Imaging 2003;19:211-17.

30 Levy WC, Cerqueira MD, Abrass IB, et al. Endurance exercise training augments diastolic filling at rest and during exercise in healthy young and older men. Circulation 1993;88:116-26.

31 Vinereanu D, Florescu N, Sculthorpe N, et al. Left ventricular long-axis diastolic function is augmented in the hearts of endurance-trained compared with strength-trained athletes. Clin Sci 2002;103:249-57.

32 Jensen-Urstad $M$, Bouvier $F$, Nejat $M$, et al. Left ventricular function in endurance runners during exercise. Acta Physiol Scand 1998;164:167-72. 


\section{PostScript}

\section{LETTERS}

\section{Month by month analysis of the number of athletic training injuries: a prospective one year study on $\mathbf{2 7 0 1}$ athletes}

Various studies have focused on sport injuries. ${ }^{12}$ In a previous report the incidence of injuries in athletes in a one year study was analysed using a sample size that was less than 150 subjects. ${ }^{1}$ It was hypothesised that subjects who were more involved in sport before injury (eight hours or more a week of sport and exercise) would exhibit a greater emotional response to injury and perceive their recovery to be less. ${ }^{2}$

In view of this we analysed a large sample of athletes (2701) who trained a minimum of 10 hours a week to see in which months of the year athletic training injuries were most common.

In a one year prospective study (from January 2004 to December 2004) we recorded the number of training injuries sustained in a month by month fashion. The mean (SD) age of the subjects was 39.62 (12.98) (range 1463).

We recorded a total of 450 athletic training injuries. The greatest number of injuries were recorded in January $(\mathrm{n}=71 ; 15.8 \%)$ followed by February $(n=64 ; 14.2 \%)$, March $(n=56$; $12.4 \%)$, May $(\mathrm{n}=54 ; 12.0 \%)$, April $(\mathrm{n}=47$; $10.4 \%)$, December $(\mathrm{n}=37 ; 8.2 \%)$, June $(\mathrm{n}=34 ; 7.5 \%)$, September $(\mathrm{n}=29 ; 6.4 \%)$, July $(\mathrm{n}=27 ; 6.0 \%)$, November $(\mathrm{n}=22$; $4.9 \%)$, August $(\mathrm{n}=7 ; 1.5 \%)$, and October $(\mathrm{n}=2 ; 0.4 \%)$

A total of 191 injuries (42.4\%) were recorded between January and March, 135 (30.0\%) between April and June, 63 (14.0\%) between July and September, and 61 (13.5\%) between October and December. The total recorded between January and June was 326 $(72.4 \%)$ compared with $124(27.5 \%)$ between July and December.

In summary, our study has shown that the number of athletic training injuries was higher during the first semester of the year than the second.

J A Sanchis-Gimeno, E Casas-Roman, C Garcia-Campero, R Hurtado-Fernandez, L Aparicio-Bellver

University of Valencia, Valencia, Spain

Correspondence to: Professor Sanchis-Gimeno Facultad de Medicina, Depto Anatomia y Embriologia Humana, Apartado correos 15038, Valencia 46080, Spain; juan.sanchis@uv.es

doi: 10.1136/bjsm.2005.019448

Competing interests: none declared

\section{References}

1 D'Souza D. Track and field athletics injuries: a one-year survey. Br J Sports Med

1994;28:197-202.

2 Johnston LH, Carroll D. The psychological impact of injury: effects of prior sport and exercise involvement. Br J Sports Med 2000;34:436-9.

\section{Effective measures to improve driver safety}

In a recent article in this journal by Leonard and colleagues, ${ }^{1}$ it was concluded that changing the configuration of motor racing circuits by introducing chicanes may significantly decrease the risk of severe injury to drivers. We believe that this evidence is reliable up to a certain point. There are several other measures that could be implemented to improve the overall safety of drivers; making circuits slower is not necessarily the only or the best strategy. From a spectator point of view, the introduction of numerous slow chicanes over the past decade, disrupting the original configuration of some legendary circuits such as Hockenheim, Imola, and Monza, has contributed to making motor racing less spectacular. From a scientific perspective, driver safety may be improved by the adoption of alternative measures that will not substantially affect the attractiveness of motor racing. Some of these are much more readily and economically applied, and may even turn out to be safer. The foremost of these measures is to increase the weight of the car and reduce engine power, which may encourage manufacturers to build more robust cockpits and slower competition vehicles. ${ }^{2}$ Next, we propose the obligatory use of efficient protective measures for the most commonly and severely traumatised body parts (head, limb, and legs), such as the recently designed HANS carbon fibre collar, thereby improving safety without affecting the spectacle. ${ }^{3}$ Finally, more efficient protective measures on circuits, such as replacing tyre barriers and metal rails with temporary crash protection barriers made of steel tubes and pads of hard foam, may absorb some of the crash energy, reducing the loading to both head and neck during dramatic decelerations up to $100 \mathrm{~g} .{ }^{4}$ As technological advances in competition are usually translated to production vehicles, these strategies may also be effective in preventing or limiting the severity of injuries from road traffic accidents outside the racing circuits.

\section{G Lippi, G C Guidi}

Ist Chimica e Microscopia Clinica, Università di Verona, Verona, Italy

Correspondence to: Professor Lippi, Ist Chimica e Microscopia Clinica, Università di Verona, Dip Scienze Morfologico-Biomediche, Verona 31734, Italy; ulippi@tin.it

Competing interests: none declared

\section{References}

1 Leonard L, Lim A, Chesser TJ, et al. Does changing the configuration of a motor racing circuit make it safer? Br J Sports Med 2005;39:159-61.

2 Nirula R, Kaufman R, Tencer A. Traumatic brain injury and automotive design: making motor vehicles safer. J Trauma 2003;55:844-8.

3 Minoyama $\mathrm{O}$, Tsuchida $\mathrm{H}$. Injuries in professional motor car racing drivers at a racing circuit between 1996 and 2000. Br J Sports Med 2004;38:613-16.
4 Elvik R. The safety value of guardrails and crash cushions: a meta-analysis of evidence from evaluation studies. Accid Anal Prev 1995;27:523-49.

\section{BOOK REVIEWS}

\section{Sports ethics: an anthology}

Edited by Jan Boxill. Published by Blackwell Publishers, 2002, £60.00 (hardcover), £17.99 (paperback). ISBN 0631216960

This is a collection of 35 papers, 10 of which were written specifically for this anthology. It presents a wide range of material, spanning specific topics, such as racial issues or drugs in sport, and also more abstract areas, such as the quality of sportsmanship. Most of the writing is by philosophers, but there are pieces representing sportspeople, physical education specialists, sports psychologists, sport scientists, journalists, a lawyer, and a basketball coach. For this reason, the book is stylistically very diverse. Fittingly, the volume closes with a 1999 piece by Rick Reilly, a writer for Sports Illustrated, written from the perspective of an 8 year old sports fan who is getting the wrong message from televised sport.

The theme of sport's corruption seems to run strongly in this collection. There seems to be an undercurrent of moral outrage at sport's degradation through commercialisation, new technology, and competition taken too far.

Editor Jan Boxill's introductory piece on the moral significance of sport, for example, defines sport in terms of four "paradigmatic" properties, all of which seem prone to "perversion". Sport, Boxill explains, can be degraded when we make a living from it, when we break rules, or when we view our sporting success as our opponent's loss. These paradigmatic qualities, Boxill says, also explain the importance of sport: it is the "single most available and the single most participated in means" for attaining self development, self expression, and self respect. "Sport is the art of the people", she claims, which sounds wonderful-yet we wonder if perhaps this amounts to a devaluation of sports fans' appreciation of sport's baser, less artistic, merits: Beckham's glamour, McEnroe's tantrums, or Mohammed Ali's propensity to verbally raise the stakes of victory. Some of the "best" sportspeople on Boxill's definition, such as Pete Sampras, are the least loved. And if sports are really "of the people", then surely the popularity of a sport is a good metric of whether or not it is headed in the right direction?

We are not so worried about the perversion of sport as most of these authors are. Boxill, like many of the authors of this volume, is an avid amateur sportsperson as well as a philosopher, and it shows in her conception of sport-a conception that is more "of the sportspeople" than "of the people". Sport evolves in ways that the sportspeople themselves are often slowest to accept, because they are most strongly affected by change. But from the point of view a sports appreciator, 
commercial sponsorship did not eliminate sportsmanship from cricket, graphite racquets failed to eliminate skill from tennis, and professionalism did not ruin the Olympics. As these changes have rolled in, participation and audience involvement have ballooned - "the people" have loved it. Nonetheless, in this book Peter Wenz's article on "Human equality in sports" decries professionalism, Kathleen Pearson presents an indictment of deliberate fouls, and all three papers on performance enhancing drugs conclude that banning drug use in sport is justified.

Whether we agree with the authors' sporting politics or not, the quality of the work selected is often very good. One of the pieces specifically written for this book is Laura Morgan's "Enhancing performance in sports: what is morally permissible", in which she looks for a new argument supporting her intuition that performance enhancements "do not belong" in sport. Her novel argument is that the use of drug enhancements is harmful to the sport, meaning that it worsens the nature of sport. The difficulty for many commentators on this issue is that they want to prohibit even harmless drugs on the basis that they make a sport unfair, but have no answer to the objection that sport is already a genetic contest which is intrinsically unbalanced and unfair. Morgan avoids this issue by placing the emphasis instead on matching contestants to produce competitive contests which will challenge every competitor. Harmless drugs, she argues, would worsen the nature of sport because they inhibit this matchmaking, and thus would undermine the "mutual quest to achieve excellence" which is the ideal goal of sport. This argument entails the rather radical conclusion that harmless drugs would be permissible in solitary, non-competitive sports. We have argued that far from perverting the spirit of sport, performance enhancement embodies the human drive to be better. To be human is to be better. Performance enhancement, we have argued, embodies the spirit of human sport.'

This is a volume that questions much of the status quo concerning how we ought to play sport, and how we ought to appreciate it, but only rarely challenges this conservative conception of what sport is all about. Those who share the authors' stance on what is valuable about sport are likely to be fully satisfied by this anthology, but for some of us, perhaps a few more challenging papers could have been presented. Boxill's introductory piece is intended to motivate an academic discourse on the nature of sport, which is an excellent goal, and the breadth of the material presented here gives this goal impressive support. This is an intriguing and comprehensively interdisciplinary collection of writing.

\section{Rating}

- Presentation

$17 / 20$

- Comprehensiveness

- Readability

$15 / 20$

- Relevance

$19 / 20$

- Evidence basis

$15 / 20$

$14 / 20$

- Total

\section{References}

1 Savulescu J, Foddy B, Clayton M. Why we should allow performance enhancing drugs in sport. Br J Sports Med 2004;38:666-70.

\section{Performance enhancing substances in sport and exercise}

Edited by Michael S Bahrke, Charles E Yesalis. Published by Human Kinetics, 2002, £43.00 (hardcover), pp 384. ISBN 0736036792

This is a worthwhile addition to the library of all who work in sport and exercise medicine whether as physician, physiotherapist, or sports scientist. It extends to over 350 pages, is straightforward to read, well arranged, and with a useful index.

The initial chapter on the history of performance enhancing substances (PES) contains considerable information on early attempts at performance enhancement within sport, with much that was new to the reviewer. It even manages a brief reference to the current Governor of California under the subject of body building and anabolic agents!

The first 300 pages consider ergogenic agents in specific groups-identifying the mode of action, likely performance gains, relevant clinical studies, potential problems resulting from use, and ending with a brief overall conclusion. The statements made are generally referenced, and the sources for these are listed extensively at the end of each chapter.

The book would appear to have been initially published some three years agomy review copy was dated 2002. As the world of PES changes very rapidly, the book inevitably predates some very significant incidents, publications, and changes in regulatory activity. There is no reference to therapeutic use exemption (TUE) certificates, nor to the 2002 IOC report on supplement contaminants. It follows that the 2004 whistle blowing on "designer drug" use by elite USA athletes is also omitted.

I attempted to use the book to find specific information on a drug that had recently been brought before the UK TUE committee for consideration. There was good information on the group to which it belonged, but only a passing reference to the drug itself. That said, the chapter-end discussion of potential benefits and disadvantages was helpful and evidence based

There is an inevitable North American slant to the text, and some of the examples cited refer to American sports that are not universal in popularity. I noted reference to a local regulatory control-the US Dietary and Supplement Health and Education Act 1994; the need for regulation of non-drug supplements is clearly in harmony with current European thought on the matter.

In the chapter on anabolics, there is what seems to be an unusual statement ( $p$ 33) "from the late 30 s to the mid 80 s, anabolic steroids were used successfully to treat depression, melancholia and involutional psychoses". This certainly hasn't been my experience of conventional UK management of any of these conditions.

B-agonists are dealt with in some depth, Clenbuterol, which is not available in the UK or the USA but is obtainable in Europe, being the most closely scrutinised. This revisited the few unpleasant memories I have of the Barcelona Olympics, where its use by two athletes caused significant problems to GB team officials. However, I could find nothing in the chapter to justify the considerable effort many of us have made in implementing recent IOC regulations in respect of permitted $\mathrm{B}$-agonist inhaler use.

One area of discussion struck a chord with me, the difference in perception of doctors and athletes-or to be precise some athletes. Doctors and sports scientists put their faith in scientific studies. Athletes, however, often place much greater importance on testimonials and internet advertorials and treat research with suspicion if not contempt.

Which raises the question: how valid are clinical studies of PES in athletes? The point is well made that there may be numerous confounders at play, and this is demonstrated in the often conflicting study results contained in many chapters. Athletes rarely use ergogenic aids in the framework that would be demanded of a clinical study. PES are not used in isolation, but rather within "cocktails" where the dosage consumed and the frequency of dosage may have little to do with their use in clinical indications and which would be rejected out of hand if forwarded to an ethics committee for consideration.

The later part of the book looks to possible future developments in doping techniques and deals with some of the more difficult areas of drug testing: its problems and limitations. In the final chapter, the legal context of PES is also considered. I'll leave the saddest quotation in the book to the end: "To be a great athlete today you need a great coach, a great chemist and a great lawyer".

I really do wish that didn't ring any bells with me

Rating

- Presentation $17 / 20$

- Comprehension $16 / 20$

- Readability

- Relevance

$15 / 20$

- Evidence basis

$13 / 20$

- Total

$16 / 20$

$77 / 100$

\section{CALENDER OF EVENTS}

\section{Osteosynthese International 2005}

15-17 September 2005, Curiohaus, Hamburg Congress-Chairman: Johannes M. Rueger,

M.D., Professor and Chair Topics:

- Innovations in intramedullary osteosynthesis

- New frontiers in osteoporosis and fracture treatment

- Current trauma research

- Special topic: Recent development in pelvic and acetabular fractures

Abstract submission deadline: 31 March 2005 
Further details: INTERCONGRESS GmbH, Martin Berndt, Düsseldorfer Str. 101, 40545 Düsseldorf-Germany. Tel: +49 $211585897-$ 80; Fax: +49 211 585897-99; Email: martin. berndt@intercongress.de; Website: www. osteoint2005.de

\section{4th European Sports Medicine Congress}

13-15 October 2005, Lemesos, Cyprus Further details: Email: pyrgos.com@cytanet. com.cy

\section{BASEM Conference 2005}

10-12 November 2005, Edinburgh, Scotland Further details: Email: BASEMinfo@ aol.com; Website: www.basem.co.uk

\section{8th International Congress of the Society for Tennis Medicine and Science}

14-15 January 2006, Melbourne, Australia
To be held immediately prior to the 2006 Australian Open tennis championships, the congress will combine presentations from international and Australian experts, including Professors Tim Noakes, Bruce Elliott, and Mark Hargreaves to stimulate discussion on topical tennis science and medicine issues.

Registrations are now open via the congress website.

Further details: Email: stms2006@meetingplanners.com.au; Website: www.stms2006. com.au

\section{3th Commonwealth International Sport Conference (CISC2006)}

9-12 March 2006, Melbourne, Australia Further details: Email: enquiries@cisc2006. com; Website: www.cisc2006.com

\section{BASEM Conference 2006}

5-7 October 2006, Oxford, UK

Further details: Email: BASEMinfo@ aol.com; Website: www.basem.co.uk

\section{CORRECTION}

doi: 10.1136/bjsm.2004.013037corr 1

C A Vella, R A Robergs. A review of the stroke volume response to upright exercise in healthy subjects ( $B r J$ Sports Med 2005;39: 190-5).

A mistake in the second sentence of the first paragraph of "Historical Perspective" has been noted:

"The theory of a stroke volume plateau developed from early research based on a few subjects during two or three exercise intensities..." should read "two to five exercise intensities".

In addition, there is a misprint in table 1. Under Ferguson et al the values in the $\mathrm{VO}_{2} \mathrm{MAX}$ column and the SVMAX (ml/beat) are incorrect and should be:

7 MT women (18-30): $\mathrm{Vo}_{2} \operatorname{MAX} 42.1 \mathrm{ml} / \mathrm{kg} /$ min, SVMAX (ml/beat) 90

9 ET women (18-30): $\mathrm{Vo}_{2} \operatorname{MAX} 64.3 \mathrm{ml} / \mathrm{kg} /$ $\min , \operatorname{SVMAX}(\mathrm{ml} / \mathrm{beat}) 121$ 